Short communication

\title{
Recovery of triphenyl phosphate from waste printed circuit boards by solvothermal process
}

\author{
Cong-Cong Zhang, Fu-Shen Zhang* \\ Research Center for Eco-Environmental Sciences, Chinese Academy of Sciences, 18 Shuangqing Road, Beijing 100085, China
}

\section{H I G H L I G H T S}

- A process for triphenyl phosphate (TPPO) recovery from PCBs was established.

- The structure of recycled TPPO was in good agreement with TPPO standard material.

- The PCBs became phosphorus-free with structure and inorganic components maintained.

- The kinetics analysis of solvothermal process was evaluated and better understood.

\section{A R T I C L E I N F O}

\section{Article history:}

Received 18 September 2013

Received in revised form 20 November 2013

Accepted 23 November 2013

Available online 27 November 2013

\section{Keywords:}

E-waste

Solvothermal technique

PFRs

TPPO

Kinetics analysis

\begin{abstract}
A B S T R A C T
Organophosphorus flame retardants (PFRs) have been largely used in waste printed circuit boards (PCBs) because of the regulation of brominated flame retardants (BFRs) in recent years. In the present study, triphenyl phosphate (TPPO), a typical PFR, contained in waste PCBs was tentatively subjected to solvothermal treatment in order for efficient recycling of this type of valuable resource. Experimental results showed that the optimum operation temperature, time and liquid to solid ratio for TPPO removal were $90^{\circ} \mathrm{C}, 120 \mathrm{~min}$ and $10: 1$, respectively. After solvothermal treatment, TPPO was transferred into the solvents and solid TPPO powder was easily recovered through vacuum rotary evaporation. The TPPO recovery efficiency reached $84.4 \%$ in a purity of $93.4 \%$ and dephosphorization efficiency of waste PCBs reached 97.3\%. Shrinking core model (SCM) indicated that both interface transfer and internal diffusion affected the recovery rate of TPPO in the solvothermal process. Fourier transform infrared (FTIR) and nuclear magnetic resonance (NMR) profiles of the recycled TPPO were in good agreement with TPPO standard material indicating that the structure of the recycled TPPO maintained after the recovery process. This work provides a clean and applicable process for PFRs recovery from waste PCBs.
\end{abstract}

(c) 2013 Elsevier B.V. All rights reserved.

\section{Introduction}

Organophosphorus flame retardants (PFRs) have been largely used in waste printed circuit boards (PCBs) because of the regulation of brominated flame retardants (BFRs) in recent years [1]. In 2004, for example, the global production volume of PFRs amounted to $14 \%$ of total flame retardants, while that of BFRs accounted for $21 \%$ [2]. These PFRs including arylated, alkylated and chloroalkylated phosphate esters are extensively used in industrial polymeric materials such as plastic, lubricants, hydraulic fluids and electrical and electronic equipments [3]. In most cases, PFRs are used as additive chemicals and not covalently bound to polymeric materials $[1,2]$, which may migrate out from the materials, emit into the surrounding environment and pose a threat to human health $[1,4]$. Take triphenyl phosphate (TPPO) as example, which is widely used

\footnotetext{
* Corresponding author. Tel./fax: +86 1062849515.

E-mail address: fszhang@rcees.ac.cn (F.-S. Zhang).
}

as a plasticizer and flame retardant in waste PCBs, it is a potent inhibitor of human blood monocyte carboxylesterase and has shown hemolytic toxicity [3]. Owing to these negative biological effects of PFRs in polymeric materials, treatment of PFRs before recycling polymeric materials is urgently desired.

Various technologies, including biotransformation [5], photochemical transformation [6] and thermal decomposition [7] have been developed for treatment of flame retardants, which mainly focused on the characterization of degradation products [8] using flame retardant chemicals without consideration of matrix effects. The reported treatments for polymeric materials containing flame retardants mainly include landfills [9], incineration [10], pyrolysis [11] and mechanical recycling [12]. Among these techniques, contamination by harmful compounds is inevitable [9-12]. Obviously, transferring flame retardants from polymeric materials to the solvent and recycle flame retardants through rotary evaporation procedure is a simple and practicable technique for disposal of flame retardants in polymeric materials. 
Supercritical carbon dioxide $\left(\mathrm{Sc}-\mathrm{CO}_{2}\right)$ extraction is a promising way to remove flame retardants from polymeric materials, in which harmless polymeric materials and high-priced flame retardants were recycled $[13,14]$. But it is noteworthy that, high pressure of $\mathrm{Sc}-\mathrm{CO}_{2}$ means high energy cost and equipment requirement, which have become challenges faced by $\mathrm{Sc}-\mathrm{CO}_{2}$ to recycle flame retardants [15]. Solvothermal process is usually conducted at lower pressure in comparison with $\mathrm{Sc}-\mathrm{CO}_{2}$. Recently, we have revealed that solvothermal process was a powerful method to remove BFRs from electrical and electronic waste plastic [16]. As a consequence, we applied this technique to transfer TPPO from waste PCBs to the solvent followed by recycling TPPO through rotary evaporation procedure. To our knowledge, only limited works focused on the occurrence and behavior of PFRs in water, indoor air and the atmospheric environment as well as analytical methods for the determination of PFRs from environmental samples $[17,18]$. There is no report focused on application of solvothermal procedure for the recovery of PFRs from waste PCBs.

The primary objective of this study was to evaluate the effectiveness of solvothermal procedure for the recovery of PFRs from waste PCBs. Effects of various conditions on the recovery of PFRs were evaluated, and a suitable procedure for PFRs recovery was established.

\section{Experimental section}

\subsection{Materials}

Waste PCBs used in this work were supplied by XIAMEN OASIS Sources Co., Ltd. The PCBs with TPPO as additive flame retardant were cut into small pieces and ground to powder by a grinder after the electronic components such as capacitors, relays were disassembled. HPLC grade acetone and methanol were purchased from J\&K Chemical Ltd., USA. Standard of TPPO was obtained from AccuStandard Inc., USA. Anhydrous sodium sulfate $\left(\mathrm{Na}_{2} \mathrm{SO}_{4}\right)$ was analytical reagent from domestic manufacturer.

\subsection{Experimental procedures}

Fig. 1 shows the schematic diagram of TPPO recovery process. Solvothermal experiments were carried out by using a series of reactors consisted of $100 \mathrm{~mL}$ Teflon interiors and stainless exteriors. In a typical run, weighed PCBs and a certain amount of methanol were introduced into the reactor. The reactor was sealed, placed into an oven and held at the desired temperature for a specified time. On the termination of the reaction, the reactor was cooled quickly to room temperature. The mixture was separated by centrifugation $(10,000 \mathrm{~g}, 10 \mathrm{~min}$, TG16-WS, China). The solid phase was allowed to air-dry overnight and subjected to analyses of X-ray diffraction (XRD) and X-ray fluorescence (XRF). The solvent phase was first concentrated on the vacuum rotary evaporator for solvent substitution with acetone and dehydrated by anhydrous sodium sulfate. Then the solvent phase was transferred to Kuderna-Danish (K-D) concentrator and evaporated to $1 \mathrm{~mL}$ using evaporation with gentle stream of nitrogen for gas chromatography-mass (GC/MS) analysis of TPPO.

Different treating temperatures $\left(50,70,90,110,130,150,170{ }^{\circ} \mathrm{C}\right)$, times $(15,30,45,60,75,90,105,120,180,240 \mathrm{~min})$ and liquid to solid ratios $(5: 1,8: 1,10: 1,15: 1,20: 1)$ were performed so as to optimize the parameters of solvothermal process. The solvent phases were collected and evaporated on the vacuum rotary evaporator to obtain recycled TPPO powder. The recycled TPPO powder was subjected to analyses of Fourier transform infrared (FTIR) and nuclear magnetic resonance (NMR).

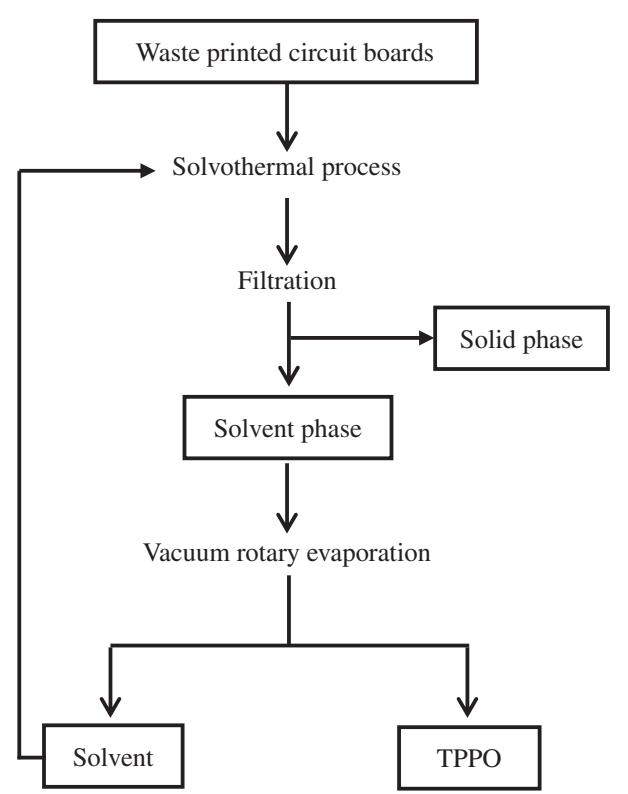

Fig. 1. Schematic diagram of TPPO recovery process.

\subsection{Analytical procedures}

The energy dispersive XRF spectrometer (XRF-1800, Schimadu, Japan) was applied for the analysis of phosphorus content in waste PCBs before and after treatment. TPPO in solvent phase was analyzed by an Agilent 7890A gas chromatograph equipped with an Agilent 5975C mass spectrometry detector and autosampler (USA). Chromatographic separation was accomplished with a HP5 capillary column ( $30 \mathrm{~m} \times 0.25 \mathrm{~mm}$ i.d. $\times 0.25 \mu \mathrm{m}$ film thickness) using splitless injections. High purity He was used as carrier gas with a constant flow rate of $1 \mathrm{~mL} / \mathrm{min}$. The column temperature of chromatographic analysis was programmed as follows: the initial temperature was set at $50^{\circ} \mathrm{C}$ and then ramped to $150{ }^{\circ} \mathrm{C}$ at $20^{\circ} \mathrm{C} / \mathrm{min}$, increased to $180^{\circ} \mathrm{C}$ at $10^{\circ} \mathrm{C} / \mathrm{min}$, finally increased to $280^{\circ} \mathrm{C}$ at $3^{\circ} \mathrm{C} / \mathrm{min}$ holding for $2 \mathrm{~min}$. The purity of TPPO was characterized by peak area ratio method of GC/MS analysis. The FTIR analysis was accomplished by in situ FTIR spectrometer (BrukerTensor27). The ${ }^{13} \mathrm{C}$ and ${ }^{1} \mathrm{H}$ NMR spectra were used to identify the recycled TPPO, which were tested in chloroform-d on a JEOL $600 \mathrm{MHz}$ spectrometer (Tokyo, Japan) at room temperature. XRD analyses of waste PCBs before and after treatment were carried out using Philips PW 1700 X-ray diffractometer.

Each experiment was carried out in triplicate for parallel test, and average values with standard errors were reported. Procedure blanks were run to determine background levels. Blank levels for the solvothermal procedure were typically $\leqslant 1 \%$ of the contents of TPPO in the samples. The presented values were corrected accordingly. Statistical analysis of the results was performed in SPSS 19.0 (SPSS Inc., USA).

\section{Results and discussion}

\subsection{Dephosphorization efficiency}

XRF analysis of waste PCBs indicated that the phosphorus content accounted for $1.83 \%$ of the total waste PCBs (wt.\%). Based on chemical formula of TPPO, it was calculated that TPPO content amounted to $19.3 \%$ of the original waste PCBs (wt.\%). After solvothermal treatment at $90{ }^{\circ} \mathrm{C}$ for $2 \mathrm{~h}$, phosphorus in the residue was reduced to $0.19 \%$ (wt.\%), indicating that $89.6 \%$ of TPPO was 
removed from the PCBs sample. Further treatment showed that only $0.05 \%$ of phosphorus was detected by XRF analysis and the dephosphorization efficiency of solvothermal treatment for waste PCBs reached $97.3 \%$. The increase of dephosphorization efficiency after further treatment was mainly relevant to the concentration of TPPO in solvothermal extract. In the initial solvothermal process, TPPO constantly diffused from the polymer into the extraction solvent since the concentration of TPPO in the polymer was higher than the extraction solvent. As the solvothermal process continued, diffusion force decreased with the decrease of TPPO concentration difference between the polymer and the extraction solvent. The increased viscosity of solvothermal extract further limited the increase of dephosphorization efficiency. The foregoing results demonstrated the feasibility of solvothermal procedure for TPPO removal from waste PCBs.

As shown in FTIR spectra (Fig. 2), similar profiles of waste PCBs were obtained before and after solvothermal treatment. The XRD patterns of waste PCBs before and after treatment are described in Fig. 3. The main characteristic peaks of waste PCBs before and after treatment correspond to copper, tin and lead. Similar XRD patterns of waste PCBs were obtained except that the intensity of tin and lead diffraction peaks slightly reduced after solvothermal treatment. This indicated that the inorganic components were greatly maintained. Since waste PCBs were also valuable resources for recovery of chemical feed-stocks and metals such as copper, solvothermal procedure is of great superiority for recovery of flame retardants especially by virtue of less damaged structure and basically unchanged inorganic components.

\subsection{Recycled TPPO}

The chromatogram of solvent phase after solvothermal treatment reveals that TPPO is the major component of the extract (Fig. 4). After further vacuum rotary evaporating treatment of this phase, brown TPPO powder was obtained, showing the impurity of the product. Fig. 4 illustrates that a small quantity of impurities was observed due to the dissolution of polymeric materials [13]. By comparing the peak areas of the GC/MS profiles for the recycled TPPO and TPPO standard material, it was calculated that the purity of the recycled TPPO was $93.4 \%$.

Obviously, as a practical technique to recycle TPPO from waste PCBs, solvothermal procedure must not significantly affect structure of TPPO. As shown in FTIR spectra of recycled TPPO and pure TPPO (Fig. 5), the band at $3100-3000 \mathrm{~cm}^{-1}$ correspond to aryl-H

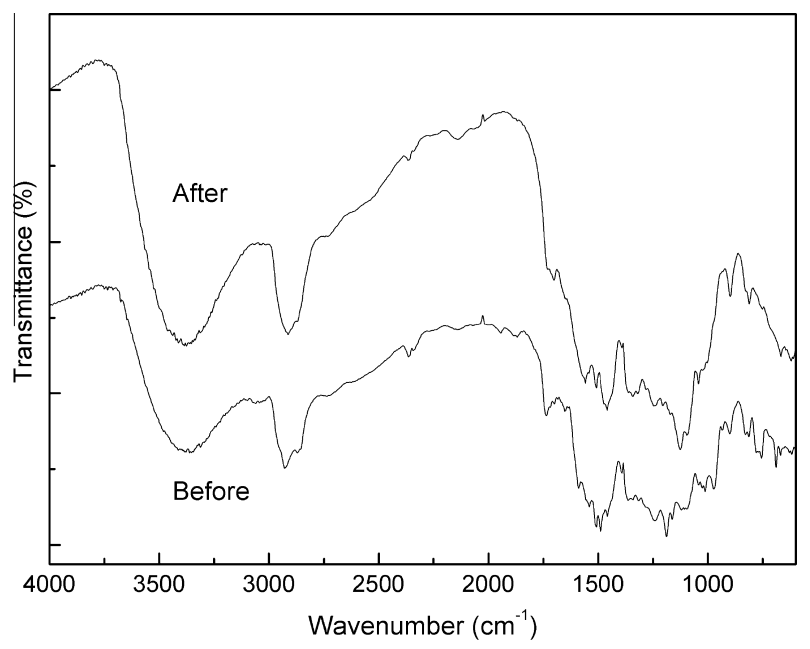

Fig. 2. FTIR spectra of waste PCBs before and after solvothermal treatment. Conditions: solvent methanol; temperature $90^{\circ} \mathrm{C}$; time $120 \mathrm{~min}$; liquid to solid ratio $15: 1$.

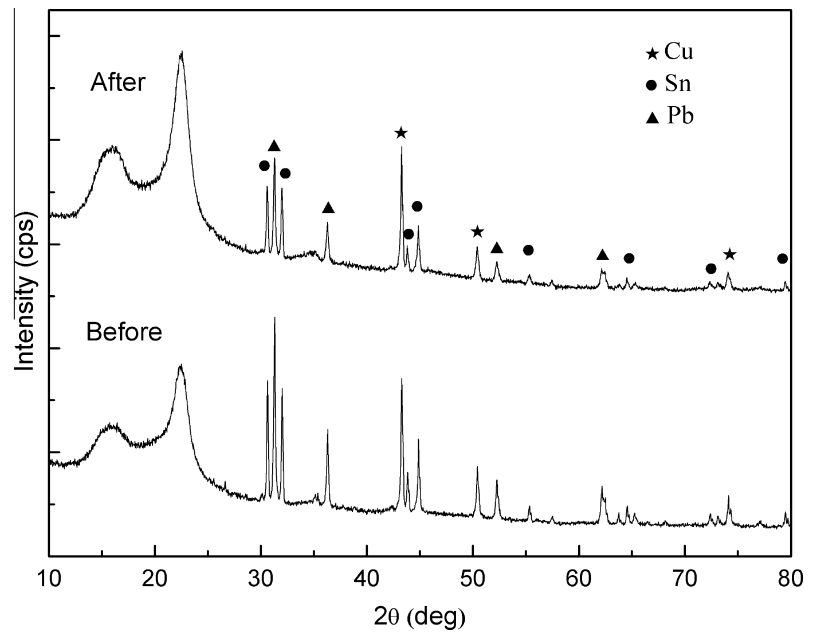

Fig. 3. XRD patterns of waste PCBs before and after solvothermal treatment. Conditions: solvent methanol; temperature $90^{\circ} \mathrm{C}$; time $120 \mathrm{~min}$; liquid to solid ratio $15: 1$.

stretching [13]; the strong peak at $1300 \mathrm{~cm}^{-1}$ is attributed to the vibration of $\mathrm{P}=0$; the broad band in the region $1220-1165 \mathrm{~cm}^{-1}$ and $965-950 \mathrm{~cm}^{-1}$ are respectively assigned to the vibrations of $\mathrm{C}-\mathrm{O}$ and $\mathrm{P}-\mathrm{O}$. Similar FTIR profiles of recycled TPPO and pure TPPO were obtained except that the peaks of pure TPPO were sharper.

The ${ }^{13} \mathrm{C}$ NMR spectra of recycled TPPO and pure TPPO (Fig. 6a) show 4 separate signals for 18 carbons present in TPPO. As demonstrated in Fig. 6a, the peak with $\delta_{\mathrm{C}}$ of $76.90 \mathrm{ppm}$ is related with the carbon of chloroform-d; the relative high chemical shift at $151.83 \mathrm{ppm}$ is assigned to the $\mathrm{C}(\mathrm{f}, \mathrm{k}, \mathrm{m})$; the signal at $129.53 \mathrm{ppm}$ is ascribed to the $\mathrm{C}(\mathrm{b}, \mathrm{d}, \mathrm{g}, \mathrm{i}, \mathrm{o}, \mathrm{q})$; the peak at $125.76 \mathrm{ppm}$ and $120.81 \mathrm{ppm}$ are respectively attributed to the $\mathrm{C}$ (c, h, p) and C (a, e, j, l, n, r). This result shows that aromatic carbon in ${ }^{13} \mathrm{C}$ NMR spectra located in the $\delta_{\mathrm{C}}$ region of $110-160 \mathrm{ppm}$ [19]. The different chemical shifts of carbon on the phenol ring were attributed to the conjugation arising from the phenol ring and oxygen, which resulted in different relative locations between carbon and oxygen. According to the ${ }^{1} \mathrm{H}$ NMR spectra of recycled TPPO and pure TPPO (Fig. 6b), the relative high chemical shift at $7.26 \mathrm{ppm}$ is assigned to the $\mathrm{H}(\mathrm{b}, \mathrm{d}, \mathrm{g}, \mathrm{i}, \mathrm{o}, \mathrm{q})$; the signal at $7.19 \mathrm{ppm}$ is ascribed to the $\mathrm{H}(\mathrm{c}, \mathrm{h}, \mathrm{p})$ and the peak at $7.15 \mathrm{ppm}$ is attributed to the $\mathrm{H}$ (a,

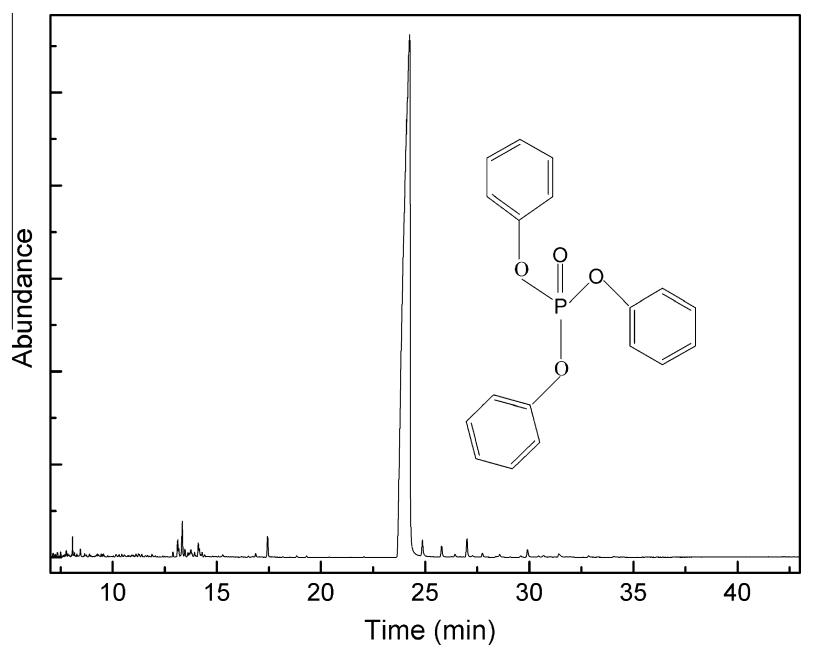

Fig. 4. GC/MS chromatogram of the solvothermal extract. Conditions: solvent methanol; temperature $90^{\circ} \mathrm{C}$; time $120 \mathrm{~min}$; liquid to solid ratio 15:1. 


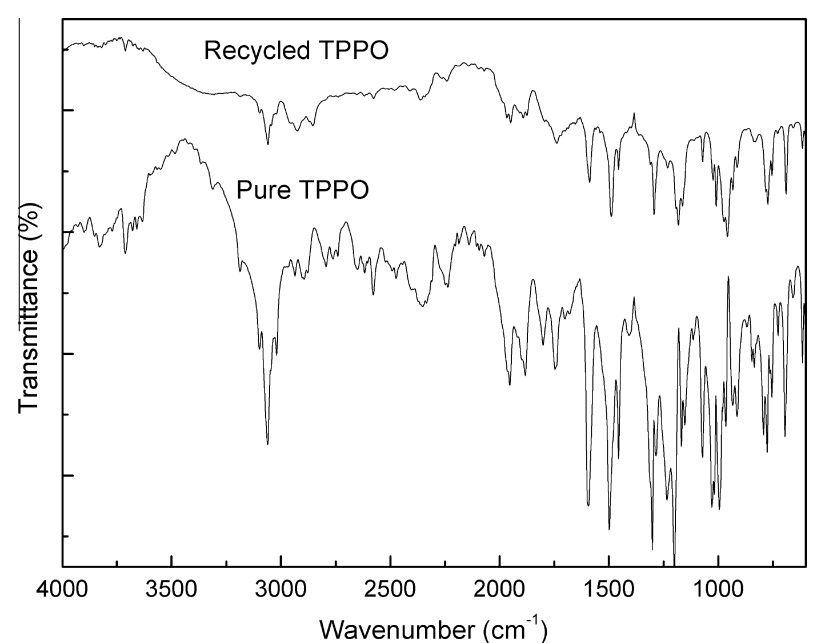

Fig. 5. FTIR spectra of the recycled TPPO and pure TPPO. Conditions: solvent methanol; temperature $90^{\circ} \mathrm{C}$; time $120 \mathrm{~min}$; liquid to solid ratio 15:1.
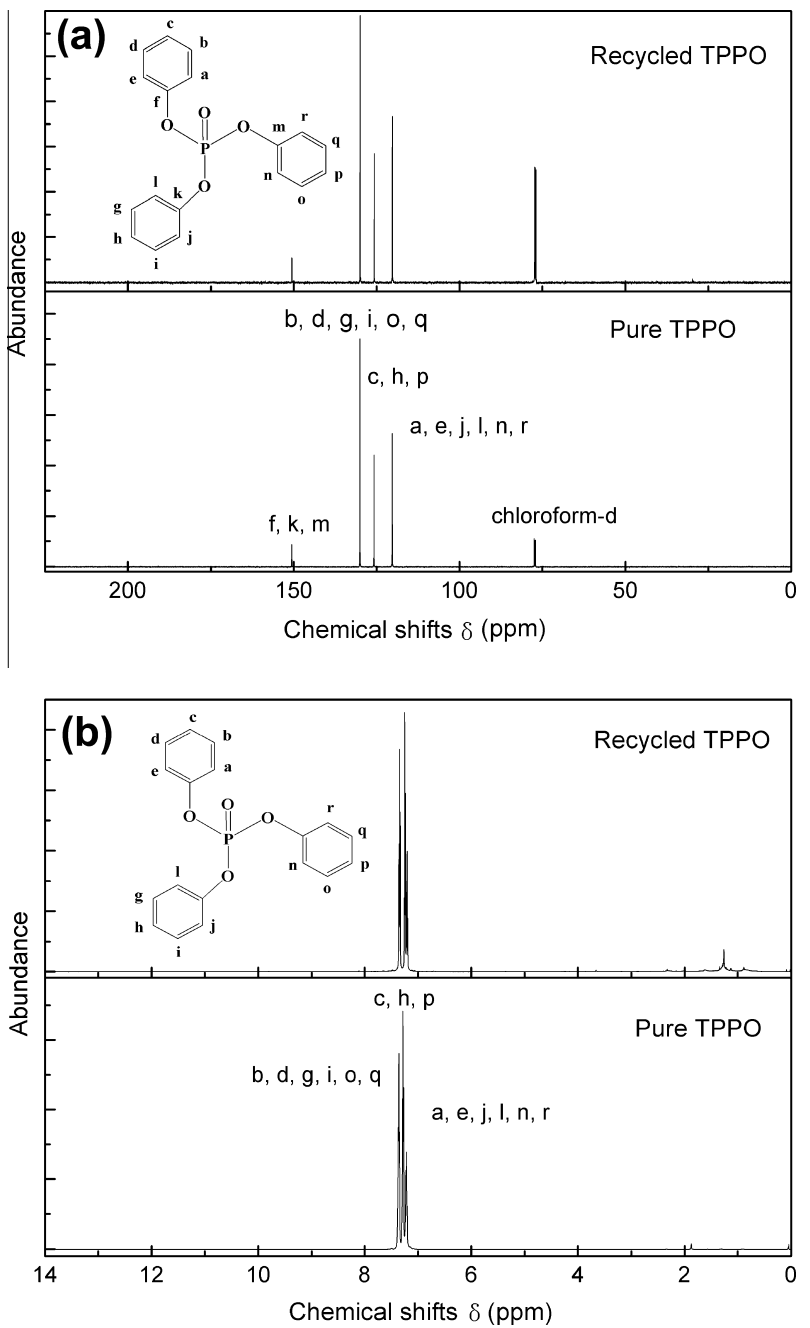

Fig. 6. NMR spectra of the recycled TPPO and pure TPPO in chloroform-d: (a) ${ }^{13} \mathrm{C}$ and (b) ${ }^{1} \mathrm{H}$. Conditions: solvent methanol; temperature $90{ }^{\circ} \mathrm{C}$; time $120 \mathrm{~min}$; liquid to solid ratio $15: 1$.

e, $\mathrm{j}, \mathrm{l}, \mathrm{n}, \mathrm{r}$ ). This indicated that the ${ }^{1} \mathrm{H}$ NMR signals of protons on phenyl ring located in the $\delta_{\mathrm{H}}$ region of $6-8.5 \mathrm{ppm}$ [19]. Similar ${ }^{13} \mathrm{C}$ and ${ }^{1} \mathrm{H}$ NMR profiles of recycled TPPO and pure TPPO further confirm that the obtained product is typical TPPO.

\subsection{Optimization of operating parameters}

Solvent property is an important factor for flame retardants removal from waste polymeric materials $[20,21]$. The solvent should have high affinity for both flame retardants and the polymeric materials and induce certain swelling effects in the polymeric materials without causing dissolution of polymeric materials [21]. Moreover, the use of hazardous solvents should be avoided. Recently, we have revealed that methanol was optimal solvent for maximum recovery and minimum loss of BFRs [16] and the range of solvents applicable in solvothermal process was much wider than conventional extraction processes due to higher temperatures and pressures, e.g., alcohol solvents, which may not perform as good extraction solvents at moderate pressure and temperature [20], were efficiently employed for solvothermal process. Methanol was thus considered for the recovery of TPPO especially due to its low toxicity.

Temperature has a dramatic effect on the removal of flame retardants from polymeric materials due to its synergistic effect on both polymeric structure and extraction kinetics [22]. And the swelling ratio between the polymeric materials and the solvent was significantly influenced by increasing temperature [22]. However, temperature should be controlled in order to avoid dissolution of polymeric materials in the solvent or collapse of polymeric structure [22]. Fig. 7 shows that the increase of temperature resulted in a remarkable increase in the extraction efficiency of TPPO from $50^{\circ} \mathrm{C}$. This is mainly because solid TPPO melts into liquid at the temperature of $50^{\circ} \mathrm{C}$ resulting in the increase in solubility of TPPO as the melting point of TPPO is $50^{\circ} \mathrm{C}$ [23]. Further increase of temperature $\left(90^{\circ} \mathrm{C}-170^{\circ} \mathrm{C}\right)$ declined the recovery efficiency of TPPO, which was attributed to degradation of TPPO. Accordingly, $90^{\circ} \mathrm{C}$ was considered as optimal temperature with the highest TPPO recovery efficiency of $77.9 \%$.

As demonstrated in Fig. 8, the recovery efficiency of TPPO increased as the prolonging of time till about $120 \mathrm{~min}$ and then reached a plateau. The highest recovery efficiency of TPPO was achieved after $120 \mathrm{~min}$ treatment. According to the phosphorus contents in the solvent phase (Fig. 9), it also should be noted that, the recovery efficiency of TPPO increased rapidly initially and then varied in a certain range as the increase of liquid to solid ratio. The highest recovery efficiency of TPPO in waste PCBs was achieved at $84.4 \%$ till the liquid to solid ratio was $10: 1$. The phosphorus contents in the solid phase were $20.1 \%, 8.1 \%, 10.4 \%$ and $10.0 \%$ of total phosphorus respectively with the liquid to solid ratio of $8: 1,10: 1$, 15:1 and 20:1. The loss of phosphorus content was calculated by

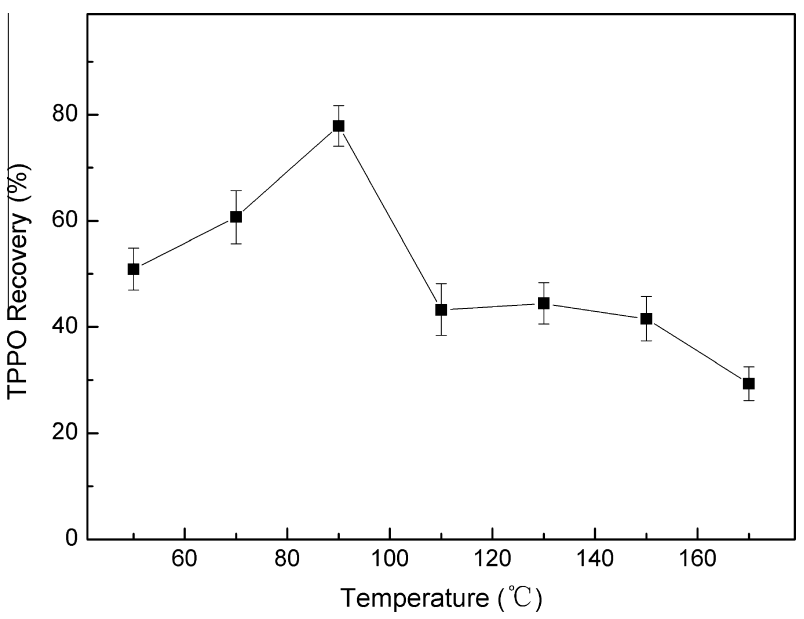

Fig. 7. Effect of temperature on TPPO recovery. Conditions: solvent methanol; time $120 \mathrm{~min}$; liquid to solid ratio $15: 1$ 
subtracting the phosphorus content of solid phase and solvent phase from the initial phosphorus content of waste PCBs. These losses of phosphorus were attributed to the solubility of TPPO in methanol [24-26]. In this case, a period of $120 \mathrm{~min}$ and a liquid to solid ratio of 10:1 were adequate to obtain maximum recovery efficiency.

\subsection{Kinetics analysis}

Similar to typical liquid-solid leaching processes [27,28], five subsequent steps was identified in the solvothermal process of removing flame retardants from polymeric materials, i.e., diffusion of solvent towards the polymer particles, diffusion of solvent through the polymer layer to the flame retardants (internal diffusion), dissolution of flame retardants into the solvent (surface dissolution), diffusion of flame retardants through the polymer layer (internal diffusion) and transfer of flame retardants from the polymer boundary into the solvent. The shrinking core model (SCM) considers that surface dissolution, internal diffusion, both the interface transfer and internal diffusion are rate controlling steps of leaching processes. Assuming that TPPO particles are spherical and the leaching process is first order reaction, the SCM could be used to illustrate the kinetics analysis of solvothermal process for TPPO removal. When the rate controlling steps are surface dissolution, internal diffusion, both the interface transfer and internal diffusion, the shrinking core model can be respectively illustrated by Eqs. (1)-(3) as follows [27,28]:

$1-(1-\alpha)^{1 / 3}=k_{1} t$

$1-(2 / 3) \alpha-(1-\alpha)^{2 / 3}=k_{2} t$

$(1 / 3) \ln (1-\alpha)+(1-\alpha)^{-1 / 3}-1=k_{3} t$

where $\alpha$ is recovery efficiency of TPPO, $k_{1}, k_{2}, k_{3}$ are rate constants, and $t$ is treatment time.

As can be seen from Eqs. (1)-(3), when the process is controlled by surface dissolution, internal diffusion, both the interface transfer and internal diffusion, the corresponding plots of $1-(1-\alpha)^{1 / 3}$, $1-(2 / 3) \alpha-(1-\alpha)^{2 / 3}$ and $(1 / 3) \ln (1-\alpha)+(1-\alpha)^{-1 / 3}-1$ versus time are straight lines with different slopes. For the kinetics analysis of solvothermal process in the present study, $1-(1-\alpha)^{1 / 3}$, $1-(2 / 3) \alpha-(1-\alpha)^{2 / 3}$ and $(1 / 3) \ln (1-\alpha)+(1-\alpha)^{-1 / 3}-1$ were plotted with respect to the treatment time and the correlation of the kinetics data with these models were assessed by using correlation coefficients in Fig. 10. As can be observed from Fig. 10, Eq. (2)

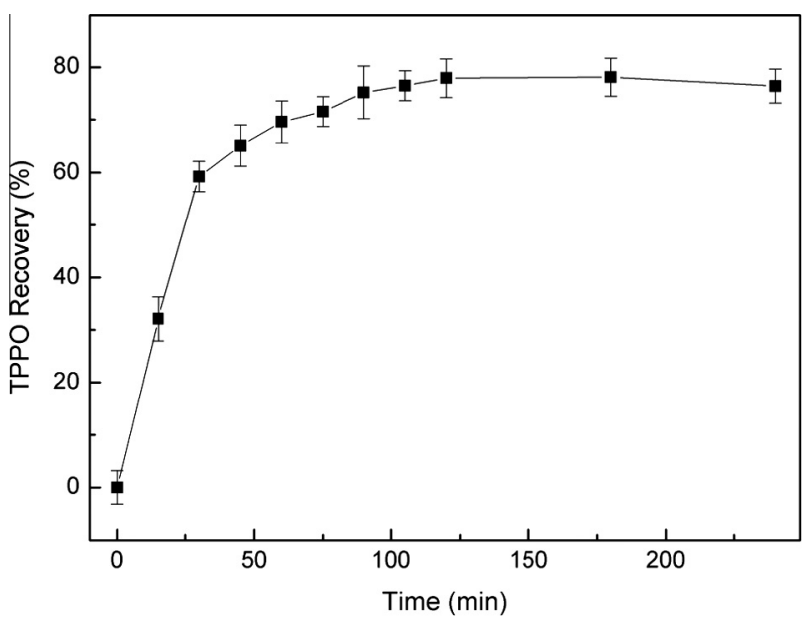

Fig. 8. Effect of time on TPPO recovery. Conditions: solvent methanol; temperature $90{ }^{\circ} \mathrm{C}$; liquid to solid ratio $15: 1$.

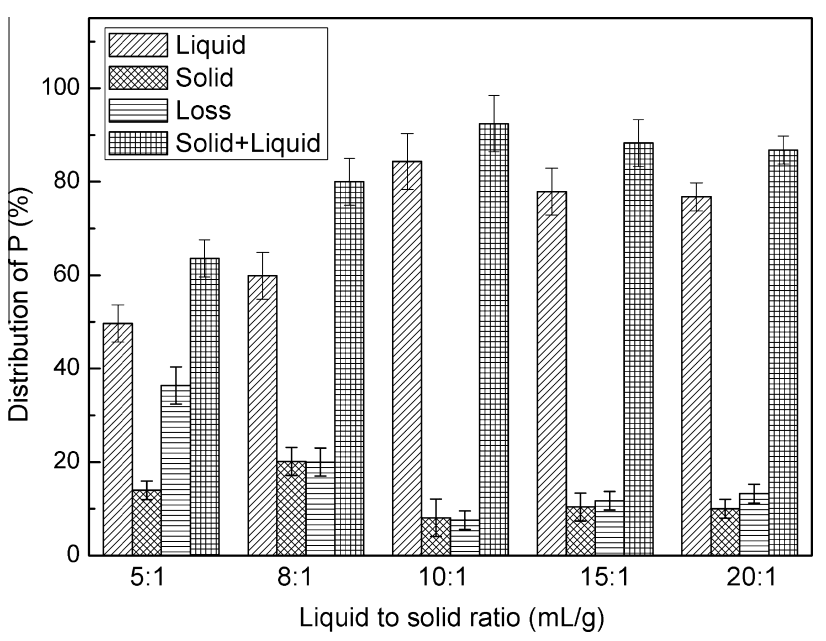

Fig. 9. Effect of liquid to solid ratio on $P$ distribution. Conditions: solvent methanol; temperature $90^{\circ} \mathrm{C}$; time $120 \mathrm{~min}$.

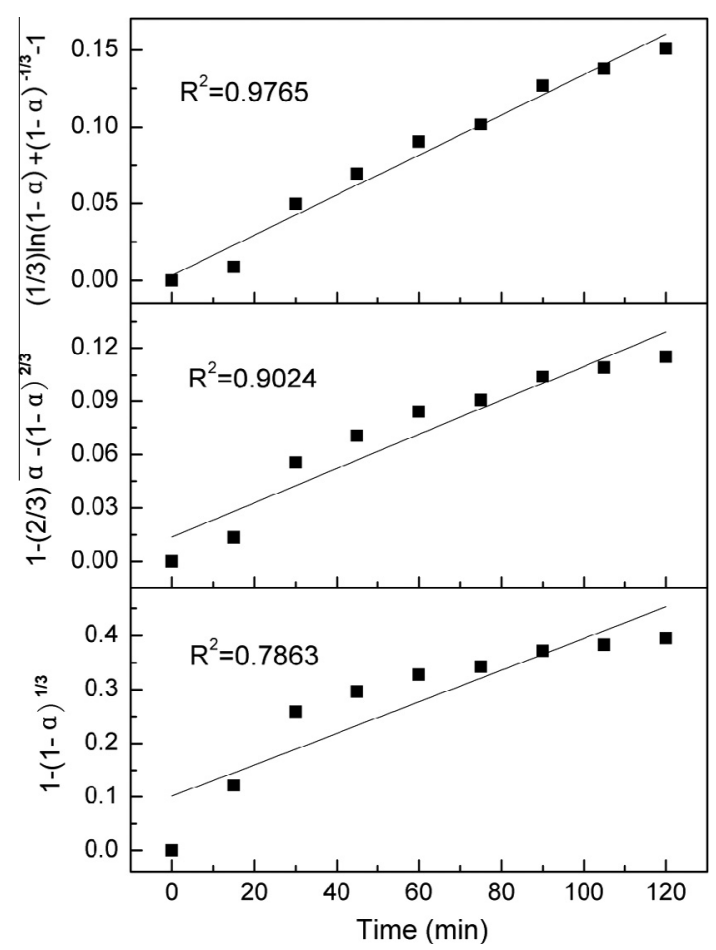

Fig. 10. Plots of $1-(1-\alpha)^{1 / 3}, \quad 1-(2 / 3) \alpha-(1-\alpha)^{2 / 3}$ and $(1 / 3) \ln (1-\alpha)+$ $(1-\alpha)^{-1 / 3}-1$ versus time. Conditions: solvent methanol; temperature $90{ }^{\circ} \mathrm{C}$; liquid to solid ratio $15: 1$.

fitted better compared with Eq. (1) and the correlation coefficient for Eq. (2) was $0.90(p<0.05)$, which meant that internal diffusion was of great significance in controlling the recovery rate of TPPO. Compared with Eq. (2), Eq. (3) takes into account the factor of interface transfer and the higher correlation coefficient of Eq. (3) $(p<0.05)$ indicates that interface transfer also plays a role in controlling the recovery rate of TPPO.

\section{Conclusions}

This study demonstrated that solvothermal process followed by vacuum rotary evaporation was a practical and efficient technique 
for recovery of additive flame retardants from waste PCBs. For waste PCBs containing flame retarded TPPO, high TPPO recovery efficiency of $84.4 \%$ with a purity of $93.4 \%$ and dephosphorization efficiency of waste PCBs at $97.3 \%$ were achieved. The optimum temperature, time and liquid to solid ratio were $90{ }^{\circ} \mathrm{C}, 120 \mathrm{~min}$ and 10:1, respectively. The recovery rate of TPPO in the solvothermal process was mainly controlled by interface transfer and internal diffusion. The structure of recycled TPPO was maintained after the recovery process, which could be easily utilized as chemical feed-stocks.

\section{Acknowledgements}

The authors are grateful for financial supports from China Postdoctoral Science Foundation (2013M530750), the National Water Pollution Control and Management Program (2012ZX07202-005), the National Natural Science Foundation of China (21077120 and 51278485) and the Science Promotion Program of Research Center for Eco-Environmental Sciences, CAS (YSW2013B05).

\section{References}

[1] J. Cristale, J. Quintana, R. Chaler, F. Ventura, S. Lacorte, Gas chromatography/ mass spectrometry comprehensive analysis of organophosphorus, brominated flame retardants, by-products and formulation intermediates in water, J. Chromatogr. A 1241 (2012) 1-12.

[2] S.H. Brandsma, J. Boer, W.P. Cofino, A. Covaci, P.E.G. Leonards, Organophosphorus flame-retardant and plasticizer analysis, including recommendations from the first worldwide interlaboratory study, TrAC, Trends Anal. Chem. 43 (2013) 217-228.

[3] H. Carlsson, U. Nilsson, C. Ostman, Video display units: an emission source of the contact allergenic flame retardant triphenyl phosphate in the indoor environment, Environ. Sci. Technol. 34 (2000) 3885-3889.

[4] A. Marklund, B. Andersson, P. Haglund, Organophosphorus flame retardants and plasticizers in Swedish sewage treatment plants, Environ. Sci. Technol. 39 (2005) 7423-7429.

[5] J.W. Voordeckers, D.E. Fennell, K. Jones, M.M. Haggblom, Anaerobic biotransformation of tetrabromobisphenol $\mathrm{A}$, tetrachlorobisphenol $\mathrm{A}$, and bisphenol A in estuarine sediments, Environ. Sci. Technol. 36 (2002) 696-701.

[6] J. Eriksson, S. Rahm, N. Green, A. Bergman, E. Jakobsson, Photochemical transformations of tetrabromobisphenol $\mathrm{A}$ and related phenols in water, Chemosphere 54 (2004) 117-126.

[7] F. Barontini, V. Cozzani, K. Marsanich, V. Raffa, L. Petarca, An experimental investigation of tetrabromobisphenol A decomposition pathways, J. Anal. Appl. Pyrolysis 72 (2004) 41-53.

[8] F. Barontini, K. Marsanich, L. Petarca, V. Cozzani, The thermal degradation process of tetrabromobisphenol A, Ind. Eng. Chem. Res. 43 (2004) 1952-1961.

[9] M. Osako, Y.J. Kim, S.I. Sakai, Leaching of brominated flame retardants in leachate from landfills in Japan, Chemosphere 57 (2004) 1571-1579.
[10] S. Sakai, J. Watanabe, Y. Honda, H. Takatsuki, I. Aoki, M. Futamatsu, K. Shiozaki, Combustion of brominated flame retardants and behavior of its byproducts, Chemosphere 42 (2001) 519-531.

[11] M.P. Luda, A.I. Balabanovich, Thermal hydrodehalogenation of 2,4dibromophenol by polymeric materials, J. Anal. Appl. Pyrolysis 90 (2011) 63-71.

[12] R. Taurino, P. Pozzi, T. Zanasi, Facile characterization of polymer fractions from waste electrical and electronic equipment (WEEE) for mechanical recycling, Waste Manage. 30 (2010) 2601-2607.

[13] A.M. Altwaiq, M. Wolf, R. van Eldik, Extraction of brominated flame retardants from polymeric waste material using different solvents and supercritical carbon dioxide, Anal. Chim. Acta 491 (2003) 111-123.

[14] T. Gamse, F. Steinkellner, R. Marr, P. Alessi, I. Kikic, Solubility studies of organic flame retardants in supercritical $\mathrm{CO}_{2}$, Ind. Eng. Chem. Res. 39 (2000) 48884890.

[15] J.Y. Guo, J. Guo, Z.M. Xu, Recycling of non-metallic fractions from waste printed circuit boards: a review, J. Hazard. Mater. 168 (2009) 567-590.

[16] C.C. Zhang, F.S. Zhang, Removal of brominated flame retardant from electrical and electronic waste plastic by solvothermal technique, J. Hazard. Mater. 221 (2012) 193-198.

[17] J.B. Quintana, R. Rodil, T. Reemtsma, M. Garcia-Lopez, I. Rodriguez, Organophosphorus flame retardants and plasticizers in water and air II. Analytical methodology, TrAC, Trends Anal. Chem. 27 (2008) 904-915.

[18] T. Reemtsma, J.B. Quintana, R. Rodil, M. Garcia-Lopez, I. Rodriguez, Organophosphorus flame retardants and plasticizers in water and air I. Occurrence and fate, TrAC, Trends Anal. Chem. 27 (2008) 727-737.

[19] S. Qiu, J. Wei, F. Pan, J. Liu, A. Zhang, Vibrational, NMR spectrum and orbital analysis of 3,3',5,5'-tetrabromobisphenol A: a combined experimental and computational study, Spectrochim. Acta A 106 (2013) 38-44.

[20] X. Lou, H.G. Janssen, C.A. Cramers, Parameters affecting the accelerated solvent extraction of polymeric samples, Anal. Chem. 69 (1997) 1598-1603.

[21] F. Vilaplana, A. Ribes-Greus, S. Karlsson, Microwave-assisted extraction for qualitative and quantitative determination of brominated flame retardants in styrenic plastic fractions from waste electrical and electronic equipment (WEEE), Talanta 78 (2009) 33-39.

[22] F. Vilaplana, P. Karlsson, A. Ribes-Greus, P. Ivarsson, S. Karlsson, Analysis of brominated flame retardants in styrenic polymers: comparison of the extraction efficiency of ultrasonication, microwave-assisted extraction and pressurised liquid extraction, J. Chromatogr. A 1196 (2008) 139-146.

[23] H.T. Wang, M. Hirahara, M. Goto, T. Hirose, Extraction of flame retardants from electronic printed circuit board by supercritical carbon dioxide, J. Supercrit. Fluids 29 (2004) 251-256.

[24] J. Hiebl, W. Vetter, Detection of hexabromocyclododecane and its metabolite pentabromocyclododecene in chicken egg and fish from the official food control, J. Agric. Food Chem. 55 (2007) 3319-3324.

[25] G.T. Tomy, T. Halldorson, R. Danell, K. Law, G. Arsenault, M. Alaee, G. MacInnis, C.H. Marvin, Refinements to the diastereoisomer-specific method for the analysis of hexabromocyclododecane, Rapid Commun. Mass Spectrom. 19 (2005) 2819-2826.

[26] Y. Zhong, P. Peng, Z. Yu, H. Deng, Effects of metals on the transformation of hexabromocyclododecane (HBCD) in solvents: implications for solvent-based recycling of brominated flame retardants, Chemosphere 81 (2010) 72-78.

[27] C. Dickinson, G. Heal, Solid-liquid diffusion controlled rate equations, Thermochim. Acta 340 (1999) 89-103.

[28] Z.X. Liu, Z.L. Yin, H.P. Hu, Q.Y. Chen, Leaching kinetics of low-grade copper ore containing calcium-magnesium carbonate in ammonia-ammonium sulfate solution with persulfate, Trans. Nonferr. Metal. Soc. 22 (2012) 2822-2830. 